\title{
LA PRIVATIZACIÓN BANCARIA EN MÉXICO, DE FRANCISCO IBARRA PALAFOX
}

\section{Héctor Miguel Fuentes CORTÉS*}

La privatización o desincorporación de los medios de producción y bienes bajo control estatal es un tema que acapara la atención de economistas y juristas, tanto en el área doctrinal como en el momento mismo de la creación del derecho positivo. Se trata de un tema muy polémico, pues es sabido que en algunos países ha fomentado la obtención de resultados favorables para la competitividad y el crecimiento de la riqueza social, en tanto que en otros ha sido catalogada como una medida antipopular y "entreguista" que pone la riqueza social en manos de unos cuantos hombres de negocios.

Tomando como presupuesto legítimo la primera proposición, en México se llevaron a la práctica, a finales del siglo pasado, diversas políticas de privatización sobre bienes económicos sujetos al control directo de la Federación. Durante el desarrollo de estos procesos se presentaron visiones encontradas acerca de la necesidad y eficacia de las medidas tomadas, especialmente durante los gobiernos de Miguel de la Madrid Hurtado y Carlos Salinas de Gortari.

Mucho se publicitó en los medios de comunicación acerca de las bondades que acarrearía para el Estado mexicano el traspaso de la gestión de bienes públicos al sector privado, incluso se llegó a señalar como referente a países de Europa que consiguieron renovar y optimizar su funcionamiento económico a través de la utilización de concesiones, licencias y adjudicaciones sobre áreas productivas de gran calado e importancia para sus respectivas sociedades.

Con ese tipo de argumentos se generaron, con presteza, las condiciones políticas y legislativas idóneas para concretar la adquisición de espacios económicos de enorme relevancia, por conducto de destacados círculos empresariales allegados al gobierno.

* Maestro en derecho de la información por la Universidad Michoacana de San Nicolás de Hidalgo,dihectorfuentes@gmail.com. 
Entre los bienes objeto de privatización trascendió el conocimiento sobre las operaciones para que la gestión de la banca mexicana fuera distribuida entre reconocidos hombres de negocios, quienes rápidamente advirtieron los beneficios que supondría obtener una porción de este medio tan significativo para la captación de recursos económicos.

De esta manera, en México la privatización bancaria se llevó a cabo teniendo como base los siguientes lineamientos:

a) La creación de un marco jurídico más propicio para los adeptos del proceso privatizador.

b) La realización de trabajos políticos encaminados a recabar experiencias extranjeras y a entablar relaciones con los sectores empresariales que arribarían a la gestión de los bancos sujetos a subasta.

c) Utilización de asesorías externas y valuaciones para la ejecución de las desincorporaciones bancarias.

Desafortunadamente, cada uno de estos lineamientos fue realizado en condiciones que, en su momento, no permitieron a la ciudadanía realizar un análisis a profundidad sobre la trascendencia y el impacto que implicaría para la economía mexicana la privatización del sector bancario.

La obra La privatización bancaria en México, desarrollada y escrita por el distinguido investigador Francisco Ibarra Palafox, aborda de manera puntual y detallada el proceso privatizador de la banca mexicana en torno a dichos lineamientos; el autor realiza un estudio pormenorizado sobre cada aspecto que involucra una acción de esta naturaleza a la luz de la ciencia jurídica, con un enérgico respaldo metodológico que arroja datos reveladores sobre la estrategia seguida por el gobierno de Carlos Salinas como la desincorporación del sector bancario. Ibarra Palafox presenta el contexto y las condiciones que motivaron el proceso de desincorporación y produjeron sus consecuencias posteriores, al señalar (2014: 15):

Aunque muchos países latinoamericanos y de otras regiones copiaron los modelos y mecanismos privatizadores de los países desarrollados, sus privatizaciones acaecieron en contextos socioeconómicos y culturales diferentes. La privatización era más sencilla para quienes otorgaban al sector privado una importante legitimidad; enfrentaban obstáculos adicionales los países que enfatizaban el papel redistributivo del Estado en la persecución de la justicia social, como México. 
Algunas preguntas relevantes a las cuales el libro responde puntualmente, que además fueron soslayadas del escrutinio público al momento en que ocurrían las privatizaciones, son las siguientes:

a) ¿Cuáles fueron las principales diferencias entre la privatización bancaria mexicana en relación con la efectuada en otros países?

b) ¿Quiénes fueron los principales participantes en los debates que se suscitaron al interior del Congreso para la emisión de la legislación que dio inicio al proceso y qué argumentos se esgrimieron?

c) ¿Cuáles fueron los empresarios y banqueros que acudieron al llamado del presidente para adjudicarse el dominio de las instituciones bancarias en oferta?

d) ¿Qué reputación tenían y cuáles eran sus antecedentes?

e) ¿Bajo qué condiciones fueron entregadas las concesiones bancarias?

Las respuestas a esas interrogantes, además de generar perplejidad para los lectores, brindan referencias muy precisas acerca del origen de los fenómenos sociopolíticos que han desencadenado el clima económico que persiste en México.

Sin duda, nos encontramos ante un documento de gran valía para comprender los efectos negativos que puede producir en las economías modernas una estrategia de privatización; particularmente cuando se pone en marcha sin la preexistencia de condiciones democráticas mínimas, como son garantizar el derecho de acceso a la información, la transparencia, rendición de cuentas, el respeto al texto constitucional, la participación ciudadana y la competencia equitativa entre competidores para asegurar un manejo responsable de las finanzas públicas.

Como se corrobora a través de su lectura (que aborda este complejo tema desde una perspectiva científica, libre de ideologías o dogmatismos), la privatización bancaria de este país se desarrolló en un contexto bastante inconveniente para producir resultados satisfactorios. Antes bien, fue un acontecimiento que adoleció múltiples insuficiencias en su planeación, las cuales se echarían de ver a la postre. Todas ellas se detallan con exactitud por el académico Francisco Ibarra al documentar, por ejemplo, que la privatización bancaria en México surgió a través de una determinación totalmente unilateral proveniente del Ejecutivo federal.

Debe entenderse, entonces, que el sistema presidencialista mexicano carecía (y ocurre hasta este momento) de frenos institucionales que restringieran las actuaciones arbitrarias o cualquier extralimitación por parte del jefe de Estado, como sí sucede en países de primer mundo, sobre todo 
en aquellos que fueron tomados como precedente al tratar de persuadir a la ciudadanía mexicana sobre la conveniencia de la determinación presidencial de ese entonces. Por lo tanto, queda manifiesto que la resolución privatizadora emergió por la vía del decreto presidencial, sin hacer un análisis riguroso en el cual se confrontaran puntos de vista especializados, sin permitir ni difundir un profundo debate público sobre la pertinencia de la medida o al menos involucrar a la ciudadanía a través de consultas o medios de democracia participativa.

Se comprende, asimismo, que hubo un sesgo informativo al momento de tomar la decisión y no se contemplaron alternativas para evaluar la po- lítica que se estaba implementando, con lo cual se incurrió en un severo - vicio de origen que, como atinadamente lo demuestra la obra del jurista Francisco Ibarra, generó un efecto dominó en contra de la economía popular, cuyos resultados se resienten entre los gobernados hasta el día de hoy.

El texto también incorpora elementos de estudio jurídico sumamente acertados, al indicar con toda precisión las modificaciones legales que se realizaron para introducir de manera lícita los instrumentos que habrían de servir a los interesados para obtener una porción de la banca a través de las subastas efectuadas por parte del gobierno federal, no solamente para la adquisición de instituciones bancarias sino de garantías formales para perpetuar la posesión ininterrumpida sobre ellas — muy a pesar de los desfalcos y latrocinios que tuvieron lugar apenas concluida la administración salinista-.

Como testimonio histórico del acontecer político moderno, la obra también pone en evidencia que muchas resoluciones gubernamentales acaecidas en México en los últimos tiempos corresponden a meros acuerdos políticos, que poco o nada tienen que ver con procurar cauces para el crecimiento económico del país. Antes bien, han funcionado como medidas emergentes para afrontar crisis políticas surgidas por la falta de democracia, legitimidad y, notablemente, por la ausencia de un Estado de derecho verdaderamente confiable.

En este sentido, es necesario dar a conocer de manera amplia y detallada cómo se ha desenvuelto el modelo económico promovido por gobiernos tecnócratas, puesto que varias de sus determinaciones aún se realizan sin supervisión ni sistemas evaluativos, lo que conlleva afrontar experiencias socioeconómicas sumamente adversas, así como estancamientos y reveses económicos que no encuentran justificación en un país con un potencial económico tan vasto como lo es México.

Como se indicó al inicio de esta reseña, e independientemente de la opinión de sus detractores, un proceso de privatización bancaria también 
puede ser calificado como legítimo y eficaz por la sociedad de un Estado, y hacia el exterior del mismo, en la medida que se implementa sistemática y racionalmente se comprueba fehacientemente su necesidad y está auspiciada por un fuerte respaldo popular.

En contraste, el Estado mexicano funge como un ejemplo aleccionador sobre lo que representa un proceso privatizador deficientemente diseñado y puesto en práctica con ineptitud, ya que los datos duros y cifras manejadas al interior del libro exponen de manera tajante el peso específico que tuvo el nepotismo al momento de subastar el sector bancario, la irresponsabilidad de los beneficiarios y el grado de impunidad que pueden obtener los miembros de ciertas clases empresariales, cuando los ciudadanos al ver cortados sus derechos democráticos y políticos, sencillamente no representan un auténtico contrapeso para evitar desfalcos o latrocinios sistemáticos.

Más aún, el contenido de este libro constituye un precedente que incentiva reclamar un sistema jurídico que verdaderamente haga efectivo el ejercicio del derecho a la información, a la democracia participativa, la repartición justa y equitativa de los bienes y recursos públicos, pues de otra manera seremos testigos en muy poco tiempo del colapso económico y social del Estado mexicano.

\section{Bibliografía del Libro RESEÑAdo}

Ibarra Palafox, Francisco, 2014, La privatización bancaria en México, México, Siglo XXI Editores. 